\title{
Keterlibatan Peran Orang Tua Dalam Pelaksanaan Blended Learning Pada Masa Pandemi Di Desa Enggal Rejo Kabupaten Pringsewu
}

\author{
Sri Ilham Nasution', Ika Mislaili Yana ${ }^{2}$ \\ ${ }^{12}$ UIN Raden Intan Lampung \\ ${ }^{1}$ sriilhamnasution@ radenintan.ac.id ${ }_{2}^{2}$ ikamislaili22@gmai.com
}

\begin{abstract}
This research describes the involvement of the role of parents in the implementation of blended learning during the covid-19 pandemic in Enggal Rejo village of Pringsewu Regency. The method in this study is qualitative with parent informants and children aged 6 to 12 years, data collection techniques using observation, interviews, and documentation. The results showed that the involvement of parents in the implementation of blended learning during the pandemic acted as facilitators, motivators, as teachers and as influences. In addition, the difficulties faced by parents include; Low educational background, weak economy, parental employment and limited time.
\end{abstract}

\section{Keywords: The Role Of Parents; Blended Learning.}

\begin{abstract}
Abstrak
Penelitian ini mendeskripsikan keterlibatan peran orang tua dalam pelaksanaan blended learning pada masa pandemic covid-19 di desa Enggal Rejo Kabupaten Pringsewu. Metode dalam penelitian ini adalah kualitatif dengan informan orang tua dan anak yang berusia 6 sampai 12 tahun, Teknik pengumpulan data mengunakan observasi, wawancara, dan dokumentasi. Hasilnya menunjukan bahwa kerterlibatan orang tua dalam pelaksanaan blended learning pada masa pandemi berperan sebagai fasilitator, motivator, sebagai guru dan sebagai pengaruh. Selain itu kesulitan yang dihadapi orang tua meliputi; latar belakang pendidikan yang rendah, ekonomi yang lemah, pekerjaan orang tua dan waktu yang terbatas.
\end{abstract}

\section{Kata Kunci: Peran Orang Tua; Blended Learning}

\section{Pendahuluan}

Pendidikan abad 21 adalah pendidikan era globalisasi yang terpengaruh dengan kemajuan (TIK) teknologi informasi dan komunikasi. Di era global kehadiran TIK sangat berperan sehingga dapat menghapus jarak, batas ruang dan waktu antar wilayah suatu negara dan bangsa. Sesuatu yang terjadi di daerah yang jauh berada di belahan dunia lain akan begitu mudah dan cepat sampai informasinya di genggaman kita. Kemajuan TIK di era global telah memudahkan segala tantangan rumit yang dihadapi manusia di masa sekarang, dan akan datang pada berbagai aspek kehidupan. Perkembangan TIK yang sangat cepat telah mengubah pandangan, cara dan pola hidup manusia. Kondisi yang bertumpu dan berorientasi pada kemajuan teknologi ini merupakan gambaran bahwa sekarang kita sedang berada pada era 4.0. Di era ini, manusia semakin bergantung pada berbagai piranti- piranti teknologi untuk mempermudah dan mempercepat pemenuhan kebutuhannya.

PenerapanTIK dalam dunia pendidikan sesungguhnya bukan sesuatu yang baru, karena TIK dan pendidikan sejak dulu memang seiring, terutama dalam penggunaan media pembelajaran dan sumber belajar. Eksistensi kehidupan era 4.0 dalam dunia pendidikan saat ini sangat terasa pada penggunaan piranti alat komunikasi berbasis komputer dan internet berupa laptop dan telepon pintar yang mampu menjalankan berbagai aplikasi untuk 
pembelajaran (e-learning). Kehadiran laptop dan telepon pintar dalam pembelajaran telah menggantikan alat-alat media pembelajaran berbasis teknologi audio-visual yang sempat berjaya di masa lalu, seperti slide projector OHP, CD-DVD, Video dan TV.

Pada sekolah-sekolah yang sudah cukup maju, meskipun belum optimal pemanfaatannya, penggunaan laptop dan telepon pintar untuk pemenuhan kebutuhan proses pembelajaran baik oleh guru maupun siswa beberapa tahun belakangan cukup marak dan sudah dianggap umum sebagai kebutuhan, bukan merupakan suatu barang mewah, mahal dan langka. Hal tersebut merupakan imbas positif dari upaya pemerintah untuk terus mendorong pendidikan yang berwawasan global dengan memanfaatkan berbagai kemudahan yang ditawarkan TIK. Sejalan dengan itu pada tahun 2014 pemerintah mengubah mekanisme ujian nasional dari semula ujian nasional berbasis kertas dan pensil (UNKP) menjadi ujian nasional berbasis komputer (UNBK) dan internet. Mencermati hal tersebut, sesungguhnya ada ataupun tidak ada pandemic Covid-19, orientasi pendidikan tetap akan mengarah kepada sistem pembelajaran yang berbasis TIK, dengan demikian, situasi kedaruratan yang ditimbulkan pandemic Covid-19 atau lainnya ternyata justeru mempercepat masyarakat dunia pendidikan di Indonesia, baik suka atau tidak suka, dan siap ataupun tidak siap, untuk berevolusi menjadi masyarakat pendidikan yang lebih maju, modern, familier dengan TIK.

Saat dunia pendidikan terguncang pandemi Covid-19 sehingga tidak memungkinkan lagi menyelenggarakan pembelajaran tatap muka antara guru dan siswa di ruang-ruang kelas karena sangat riskan menjadi media kluster penularan Covid-19, maka kehadiran berbagai aplikasi pembelajaran berbasis TIK yang mengarahkan proses pembelajaran dilakukan secara daring (online) menjadi solusi penting untuk menanggulangi krisis pendidikan. Hal ini juga terkait dengan kebijakan pemerintah yang tertuang dalam Surat Keputusan Bersama (SKB 4 Menteri); Kementerian Pendidikan dan Kebudayaan, Kementenrian Agama, Kementerian Kesehatan, dan Kementerian Dalam Negeri RI No 04/kb.2020, No 737 2020, No Hk. 01.08/ Menkes/ 7093/2020, No 420-3987 2020, tentang panduan penyelenggaraan pembelajaran tahun ajaran 2020/2021 dan tahun ajaran akademik 2020/2021 di masa pandemic Coronavirus disease 2019 (Covid-19) yang mengharuskan pelaksanaan pembelajaran dilakukan dari rumah secara jarak jauh (PJJ) secara daring.

Pembelajaran secara daring dapat dilakukan menggunakan berbagai program aplikasi berbasis internet, seperti program Zoom, Google meet, classroom, elearning, Whatshap, dan lain-lain yang dapat diakses menggunakan perangkat komunikasi. Pembelajaran secara daring juga memiliki karakteristik baik kelebihan maupun kekurangan. Dalam kenyataannya, pembelajaran secara online selama Pandemi Covid-19 dianggap bermasalah karena sekolah dan guru belum siap, tidak efektif, membosankan, berbiaya mahal, serta merepotkan orang tua. Dalam penelitian Iis Dahlia dan Ucup Supriatna, (2021) tentang tangapan orang tua dengan pembelajaran online pada masa pandemic covid-19, menunjukkan bahwa pada umumnya orang tua tidak setuju dengan pembelajaran online, karena mereka menganggap pembelajaran online tidak efektif, di samping itu guru dalam mengunakan media pembelajaran kurang beragam dan boros biaya kuota internet sehingga membebani orang tua terutama dari keluarga pas-pasan. Selanjutnya hasil penelitian Ayund Sabrina Sormin dkk. (2021), menunjukkan bahwa persentase kaum ibu yang mengalami stress akibat pelaksanaan pembelajaran daring covid-19 dan belum sangup menjalani era 4.0 menuju 5.0 mencapai $93,33 \%$.

Latar belakang belum siapnya penyelenggaraan pembelajaran secara daring sesungguhnya tidak hanya bertumpu kepada SDM guru, tetapi juga terjadi pada sekolah, siswa, dan orang tua. Hal ini sangat dimaklumi, mengingat peristiwa pandemic dahsyat yang mengguncang berbagai aspek kehidupan dan menimbulkan ketakutan secara massal ini merupakan peristiwa yang belum pernah terjadi sebelumnya, baru dialami pada generasi dekade saat ini, tidak pernah diduga. Kondisi tersebut bahkan dianggap sebagai kondisi darurat yang mengharuskan sekolah menerapkan pembelajaran daring untuk yang pertama kalinya. 
Bahkan tuntutan keterlibatan orang tua untuk mendampingi anak-anaknya secara lebih intens pun baru terjadi di masa pandemic saat ini. Sebagaimana keterlibatan orang tua pada penelitian Cindran Suryaputri dkk (2020), menjelaskan bahwa pola asuh orang tua menujukan orang tua yang bijaksana dalam menyikapi anak ketika belajar, dengan mendampingi anak barmain sambil belajar, orang tua yang pesimis membiarkan perilakau dan aktifitas anak. Orang tua otoriter selalu menerapkan aturan ketat dan menberikan sangsi jika anak melanggar, seperti bersikap tegas pada anak. Tidak banyak orang tua yang melaksanakan pola asuh lalai, pola asuh yang membebaskan anak dalam belajar.

Metode pembelajaran blended learning dapat menjadi solusi mengatasi pembelajaran secara online pada masa pandemic ini. Pembelajaran secara online siselingi dengan tatap muka atau yang disebut dengan pembelajaran blended learning. Dziuban dkk. (2004), mengemukakan,bahwa bended learning dapat memotivasi minat siswa dalam belajar, blended learning lebih bagus bila dibandingkan dengan pembelajaran secara daring. Pembelajaran blended learning menyatukan antara tatap muka dan daring, Bielawski dan Metcalf dalam Husamah, (2014). Dengan penerapan blended learning, diharapkan proses pembelajaran menjadi lebih variatif dan dapat mengurangi kebosanan siswa. Namun demikian, agar pembelajaran secara blended learning berdampak secara efektif keterlibatan orang tua tentu tetap dibutuhkan dalam fungsi kontrol, mediator, fasilitator, dan motivator bagi putra-putrinya. Hal ini mengingat dalam pembelajaran blended learning guru secara periodik masih tetap menerapkan pembelajaran secara online bukan secara tatap muka langsung antara siswa dan guru. Menurut hasil penelitian Umi Hanifah, Mar"atus sholikah (2021), orang tua ketika mendampingi dan membimbing anak dalam pelaksanaan blended learaning ada lima peran, yaitu sebagai fasilitator, guru, motivator dan pengaruh. Agar pelaksanaan blended learning memiliki persamaan dalam efektifitas dengan pembejaran yang dilaksanakan di sekolah, maka ke lima peran orang tua tersebut harus di laksanakan.

\section{Metode}

Penelitian adalah penelitian lapangan (field resedch) dan bersifat deskriptif, yang menjadi informan adalah 95 orang tua yang anaknya sedang pelaksanaan pembelajaran blended elearnig di desa Enggal Rejo Kabupaten Pringsewu. Teknik penentuan informan mengunakan Snowball Sampling dengan kriteria yaitu: 1) Keluarga yang mempunyai anak sedang sekolah TK-SD dan berusia 6 sampai 12 tahun, 2) Keluarga yang memiliki anak sedang pelaksanaan Blended Learning, 3) Keluarga yang bersedia di wawancarai. Teknik pengumpulan datanya mengunakan observasi yaitu mengamati orang tua dan anak yang melaksanakan pembelajaran blended learning, kemudian wawancara yaitu mewawancarai keluarga yang mempunyai anak TK/SD selanjutnya dokumentasi. Kemudian dalam menganalisis data mengunakan teori Miles and Huberman dengan langkah-langkahnya sebagai berikut: reduksi, menyajikan, verifikasi.

\section{Hasil Dan Pembahasan}

Berikut tabel pekerjaan orang tua di desa Enggal Rejo Kabupaten Pringsewu:

Tabel 1. Pekerjaan Orang Tua

\begin{tabular}{clc}
\hline No & \multicolumn{1}{c}{ Pekerjaan Orang Tua } & Jumlah \\
\hline 1 & Petani & 93 \\
\hline 2 & PNS & 1 \\
\hline 3 & Wiraswasta & 1 \\
\hline & Jumlah & 95 \\
\hline
\end{tabular}

Sumber: Dokumentasi desa Enggal Rejo Kabupaten Pringsewu

Berdasarkan tabel 1 tersebut dapat dilihat bahwa pendapatan perekonomian orang tua di desa Enggal Rejo Kabupaten Prinsewu rendah, sehingga untuk memenuhi kebutuhan hidup 
anak-anak dalam pelaksaan blended elearning mengalami kesulitan, karena masih di bawah standar atau perekonomian orang tua di Desa Enggal Rejo Kabupaten Pringsewu lemah.

Berikut ini adalah tabel pendidikan orang tua di desa Enggal Rejo Kabupaten Pringsewu

Tabel 2. Pendidikan Orang Tua

\begin{tabular}{clc}
\hline No & \multicolumn{1}{c}{ Pendidikan } & Jumlah \\
\hline 1 & SD/Sederat & 21 \\
\hline 2 & SMA/Sederajat & 68 \\
\hline 3 & S-1 & 6 \\
\hline & Jumlah & 95
\end{tabular}

Sumber: Dokumentasi Desa Enggal Rejo Kabupaten Pringsewu

Berdasarkan tabel 2 dapat dilihat bahwa Pendidikan orang tua di desa Enggal Rejo Kabupaten Pringsewu, rendah sehingga dalam pelaksaanan blended elearning orang tua sebagai fasilitator, motivasi dan sebagi guru dirumah mendapatkan kesulitan.

\section{Keterlibatan Orang Tua pada Pelaksanan Blended Learning Pada Masa Pandemi}

Keterlibatan orang tua pada pelaksanaan blended learning pada masa pandemi mengalami perubahan dalam kehidupan keluaganya. Dalam kehidupan sehari-hari seperti halnya salah satu orang tua mengungkapkan bahwa dalam pelaksanaan online ini membuat anak menjadi males dalam belajar dari rumah karena terlalu banyak tugas-tugas yang diberikan oleh guru. Dengan adanya fenomena ini keterlibatan orang tua sangat penting sekali, agar anakanak tetap menjalani kehidupan yang baru ini dengan kondisi nyaman dan semangat setiap harinya, peran tersebut diantara adalah:

a. Sebagai Fasilitator

Keterlibatan sebagai fasilitator bagi anak-anaknya, seorang anak menganggap orang tua itu adalah tempat dimana dia dapat memenuhi segala keinginannya, apalagi dimasa pandemi ini. Dengan pelaksanaan blended elearnig ini orang tua harus menyediakan segala kebutuhan anaknya, agar mereka merasa nyaman dan tidak merasa terbebani. Pada masa pandemi ini orang tua harus memfasilitasi kebutuhan anak saat belajar seperti memberikan fasilitas kuota, smartphone dan ruang belajar yang nyaman untuk anak-anak mereka dan memberikan fasilitas peralatan pembelajaran, apabila orang tua sudah memenuhi segala yang dibutuhkan anak saat pembelajaran blended learning, tentu akan menbuat anak merasa nyaman dan tenang (Arianti, 2019, p.61)

b. Sebagai Motivator

Keterlibatan Orang tua dalam memotivasi, anak-anaknya dalam pelaksanaan blended learning sangat di butuhkan agar anak tidak merasa jenuh dengan materi-materi yang di berikan oleh guru. adanya pelaksanaan blended learning ini orang tua harus memberikan motivasi agar anak-anak mereka tetap semangat dalam menjalani hari-harinya karena pelaksanaan blended learanig anak males dan kehilangan semangatnya dalam belajar. Orang tua harus menciptakan suasana yang nyaman. (Sefia S, Rambewars. 2018: 204)

c. Sebagai Guru

Keterlibatan orang tua sebagai guru dalam pelaksanaan blended learning pada masa pandemi ini sangat berperan penting bagi anak-anak mereka yakni menjadi guru di rumah mereka sendiri. Keterlibatan peran orang tua mendampingi, membimbing ketika anak membuat tugas dari guru. Setelah orang tua menemukan jawabannya di google barulah orang tua menjelaskkannya kepada anak mereka. Dengan demikian anak dapat belajar dengan nyaman dan efektif, karena orang tua mendampingi anak dalam pelaksanaan blended learning ini. (Mar'atus Sholikah, Umi Hanifah, 2021:10) 


\section{d. Sebagai Pengaruh}

Keterlibatan orang tua sangat berpengaruh bagi anak-anak mereka apalagi dalam pelaksanaan blended learning ini, orang tua sangat berpengaruh positif kepada anaknya, pengaruh rasa senang, kalau orang tua senang, anak pasti akan senang. Disamping itu orang tua sebagai pengaruh bagi anak-anaknya, dijadikan panutan bagi anak-anaknya. (Winingsih, Endang. 2020)

\section{Kesulitan Yang Dihadapi Orang Tua Dalam Pelaksanaan Blended Learning}

Disamping keterlibatan orang tua sebagai fasilitator, motivator, sebagai guru dan sebagai pengaruh, agar anak merasa nyaman dalam pelaksanaan blended elearning masa pandemi ini, Orang tua juga mengalami kesulitan dalam mendampingi dan membimbing anak-anaknya dalam pelaksanaan blended elearnig ini. Berdasarkan jawaban dari orang tua dan mengamati tabel 1 tentang mata pencarian orang tua dan tabel 2 tentang pendidikan orang orang tua maka kesulitan yang dihadapi adalah:

a. Rendahnya pendidikan orang tua

Berdasarkan jawaban dari orang tua dan memperhatikan tabel 2, latar belakang pendidikan sangat berpengaruh dalam mendampingi dan membimbing anak pada pelaksanaan blended elearning ini. Terkadang orang tua kesulitan dalam mendampingi anak ketika mengerjakan tugas-tugas anak. Dengan latar belakang pendidikan yang minim sangat sulit untuk memahami anak-anak mereka. (Pratidina Okta Nirmala, dkk. 2020)

b. Tinggkat ekonomi orang tua

Berdasarkan tabel 1 bahwa tingkat perekonomian sangat berpengaruh untuk anak-anak, apalagi dengan adanya pelaksanaan blended learning dimasa pandemi ini, merupakan suatu problematika bagi orang tua yang memiliki ekonomi lemah. Dengan pelaksanaan blended elearning ini menuntut orang tua untuk menfasilitasi anak mereka sebuah handphone lengkap dengan isi kuota internetnya, jika orang tua tidak memiliki handphone maka anak mereka tidak dapat infomasi dari sekolahnya. (Melisa Putri, dkk 2021)

c. Jenis Pekerjaan orang tua

Orang tua harus bekerja dari pagi hingga petang, sehingga mengalami kesulitan untuk perhatian, mengawasi dan membimbing anaknya setiap hari dalam pelaksanaan blended learning, sehingga waktu untuk mendampinggi anak-anak dalam mengerjakan tugas hanya pada malam hari, dalam mengumpulkan tugas tidak tepat waktu. (Andi Anugrahana, 2020)

d. Waktu yang tersedia

Orang tua juga mengalami keterbatasan waktu dalam membagi antara pekerjaan, mengurus rumah tangga mendampingi anak-anak mereka, dalam pelaksanaan pembelajaran blended learning. Sesibuk apapun orang tua dengan aktifitasnya, harus meluangkan waktu untuk berkomunikasi dan membimbingan anaknya, terutama membimbingan belajar di rumah. (Hendri Aditia Rigianti, 2020)

\section{Kesimpulan}

Keterlibatan orang tua pada pelaksanaan blended learning pada masa pandemi covid19 di Desa Enggal Rejo Kabupaten Pringsewu antara lain: a) keterlibatan orang tua sebagai fasilitator memenuhi segala yang dibutuhkan anak-anak mereka agar anak-anak tetap merasa nyaman. b) Keterlibatan orang tua sebagai motivator, selalu memberi semangat kepada anakanak mereka agar anak tidak pesimis. c) Keterlibatan orang tua sebagai guru adalah selalu membimbing dan mendidik anak-anaknya di rumah. d) Keterlibatan orang tua berpengaruh pada perkembangan dan kemajuan anak-anak. Tantangan yang di hadapi orang tua pada pelaksanaan blended learning ini adalah pendidikan orang tua yang rendah, perkonomi keluarga yang minim, harus bisa membagi waktu antara pekerjaan dan mendampingi anak membuat tugas sekolah, kurang waktu dalam membimbing dan mendampingi anak. 


\section{Daftar Pustaka}

Arianti. (2019). Urgensi Lingkungan Belajar Yang Kondusif Dalam Mendorong siswa Belajar Aktif. Didaktika, 1(1) 61

Andi Anugrahana. (2020). Hambatan, solusi dan Harapan: Pembelajaran Daring Selama Masa Pandemi Covid-19 Oleh Guru Sekolah Dasar. Scolaria:Jurnal Pendidikan dan Kebudayaan. Vol. 10 No. 3 September

Beatus M. Laka, Sefia S, Rambewars, Naftali Meokbun. (2018). Peran Orang Tua Dalam Meningkatkan Motivasi Belajar di SD Negeri Saribu. Jurnal Edumat Sains.2 (2) Januari

Charles D. Dziuban, Joel L. Hartma, Patsy D. Moskal. (2004). Blended Learning. Research Bulletin. Vol 7. No. 1 March 30

Cindra Suryaputri, Nur Hidayati, Hernik Farisia, Khoirulliati. (2020). Tren Pola Asuh Orang Tua Dalam Pendampingan Model Pembelajaran Blended Learning Pada Masa Pandemi Covid-19. TELED: Jounal of Early Childhood Education and Development. Vol 2. No. 2 Desember

Djamrah, Syaiful Bahri. (2014). Pola Asuh Orang Tua dan Komunikasi Dalam Keluarga. Jakarta: PT. Rimeka Cipta.

Eko Kuntarto, Melisa Putri, Alir Mansyah. (2021). Analisis Kesulitan Belajar Siswa Dalam Pembelajaran Daring di Era Pandemi (Studi Kasus Pada Siswa Kelas III SD). Auladan: Jurnal Pendidikan Dasar Islam Vol. 8 No. 1 Juni

Hendri Aditia Rigianti. (2020). Kendala Pembelajaran Daring Guru Sekolah Dasar Di Kabupaten Banjarnegara. Elemenatary School, Vol 7, No 2 Juli

Husamah. (2014). Pembelajaran Bauran, Blended Learning, Jakarta : Prestasi Pustaka Publisher.

Haryono, Cosmas Gatot. (2000). Ragam Metode Penelitian Kuantitatif Kualitatif. Bandung. CV. Jejak Anggota IKAPI

Muhaimin, Sutiah dan Sugeng Listyo Prabowo. (2009). Manajemen Pendidikan. Jakarta: Kencana.

Muhammad Iqbal Baihaqi, Adin Fauzi. (2021). Studi Naratif Keterlibatan Orang Tua Dalam Pembelajaran Daring Pada Masa Pandemi. Prosiding Seminar Nasional Kependidikan Sekolah Dasar Dan Prasekolah.

Purwanto. (2000). Ilmu Pendidikan Teoritis dan Praktis. Bandung: PT. Remaja Rosdakarya

Ramdanil Mubarok. (2021). Peran Kepemimpinan Dalam Keluarga Pada Pembelajaran Daring Di Desa Sangatta Utara. Aksara: Jurnal Ilmiah Pendidikan Nonformal Vol 07 (03) Septembet

Sholikah dkk, (2021). Peran Orang Tua Dalam Membantu Belajar anak di Masa Pandemi Covid-19. Pembelajaran: Jurnal Ilmu Pendidikan Keguruan, dan Pembelajaran Vol 5 Nomor 1 April

Sabrina dkk. (2021). Dampak 5.0 Daring Bagi Ibu Dan Kesiapan Menjalani Era 4.0 Menuju 5.0 Setelah Pandemi. Ristekdil ( Jurnal Bimbingan dan Konseling ) Vol 6. No. 2.

Sugiyono, (2018). Metode Penelitian Kualitatif, Bandung: CV. Alfbeta.

Suwandi Jumar. (2020) Evaluasi Program Pendidikan Madrsasah Ramah Anak. Bandung. CV.Adanu Abimatu.

Suryana, Vita Biljana Bernadethe Lefoon dan Yana. (2017). Tujuan Psikologi Hukum Dan Perlindungan anak. Yogyakarta: CV. Budi Utama.

Ucup Supriatna, Iis Dahlia (2021). Persepsi Orang Tua Terhadap Pembelajaran On Line Masa Pandemi Covid-19. Genta Mulia: Jurnal Ilmiah Pendidikan Vol XII No 2 Juli 2021

Umi Hanifah, Mar'atus sholokah. (2021). Peran Orang Tua Dalam Membantu Belajar Anak Di Masa Pandemi Covid-19. Pembelajar: Jurnal Pendidikan, Keguruan, dan Pembelajaran. Volume 5 Nomor 1 april 
Vaneshia Auralia Medida, Pratidina Okta Nirmala, Vivin Aslika Widianti. (2020). Peran Orang Tua Dalam Pendampingan Pembelajaran Daring. Seminar Nasional Pendidikan IPS Vol 1. No. 1. Conference.um.ac.id/index.php/ips/article/view/file/478/428

Wining, Endang. (2020). Peran Orang tua Dalam Pembelajaran Jarak Jauh. Diakes. Pada Tanggal 1 Agustus melalui https://poskita.co/2020/peran-orang-tua-dalampembelajaran-jarak-jauh. 